\title{
Percent Recovered Infinity Predicted Normalized by Weight
}

National Cancer Institute

\section{Source}

National Cancer Institute. Percent Recovered Infinity Predicted Normalized by Weight. NCI Thesaurus. Code C112394.

The percentage of the recovered administered dose extrapolated to infinity, calculated using the predicted value of the last non-zero concentration, divided by the weight. 